\title{
Nature Influencing Characters- An Analysis of the Malayalam Movie Iyobinte Pusthakam
}

Merin Josephine A.

PG and Research Department of English

Fatima Mata National College (Autonomous)

Kollam, Kerala, India

Dr. Cynthia Catherine Michael

Associate Professor and Head

PG and Research Department of English

Fatima Mata National College (Autonomous

Kollam, Kerala, India

cynthiamichael2006@yahoo.com

\section{Abstract}

Space and place are two complex concepts in literature. These can in turn affect the course of characters, situations and the plot of story. Presently in visual media, especially in movies; a relation between nature and surroundings can be traced. Both nature and surroundings influence each other. Malayalam cinema is going through many different paths which are always open for study. Each movie in it is incomparable in plot, techniques and narration. A relation between surroundings and characters can always be drawn. Keith H. Basso is an important cultural anthropologist who found a noticeable connection between nature and human beings. Nature always creates mystery and wonder. Nature always has a great influence in the human evolution and culture formation. Tagore's 'The Religion of Forest' says the link between forest and ancient Indian culture. In the same essay, Tagore represents 
the European belief on nature as a war between good and evil. 'IyobintePustham' is analysed in both these views. The forest depicted in the movie can be interpreted as a provider and protector to its character. In another sense, it mirrors the goodness and the evils in the mind of characters. Forest is an important archetype in human history and culture.

Keywords- Nature, Forest, Characters, Archetype

Keith H. Basso's 'Wisdom Sits in Places- Landscape and Language among Western Apache'explains the relation between nature and people. Through this book, Basso explains how nature is a part of culture and lifestyle for the people of Arizona. He highlights the idea of place upon self and self upon place. According to him there is connection between nature and man which can be seen below:

As places animate the ideas and feelings of persons who attend to them, these same ideas and feelings animate the places on which attention has been bestowed, and the movements of this process-inward toward aspects of the external world, alternately both together-cannot be known in advance. When places are actively sensed, the physical landscape becomes wedded to the landscape of the mind, to the roving imagination, and where the mind may lead is anybody's guess.(Wisdom Sits in Places: Landscape and Language among Western Apache by Keith Basso)

In Malayalam Cinema this concept becomes applicable in many movies. But it is best suited for the movie 'IyobintePusthakam'. Here the central force is forest which governs all the characters. Its influence can be seen throughout the story. Here more than a landscape and background, it is a character. The central traits of forest become the traits of characters too. Forest becomes the witness of all events and happenings. Besides the story plot, there is an indication of urbanization and liberalism. How forest influences characters and their traits can be seen below. 
"IyobintePusthakam" is an Indian Malayalam period movie set in $20^{\text {th }}$ Century. The film depicts a period spanning from pre-Independence era to the period of emergence in 1975. It was directed by Amal Neerad and co-produced by Fahadh Fazil and Amal Neerad. It stars FahadhFazil, Lal, ReenuMathhews, Kottayam. The film is set in Munnar, Western Ghats and Wagamon, Kottayam. The film is a period drama saying the story of rivalry between sons of Iyob i.e. lvan and Dimitri with Aloshy. It says the age-old story of jealousy, rivalry and death between siblings which is seen right from Genesis.

The background of the story is forest. Forest has a major role and its omnipresence can be seen throughout. Forest is the life giver, life saver and life destroyer. Forest is the redeemer and the sustainer of life. The presence of forest in the film is the conflict between absence and presence. The physical nature of forest can be seen in the film; but its power and influence is unseen. Moreover, the traits of forest can be seen in characters. Forest reacts to each character differently. Every change in the characters are observed by forest and related to it. Many manly elements are equated with the wild elements of forest. Forest rejects whoever comes to destroy the balance of forest. The forest no more gives them a shelter.

This paper analyses how Forest becomes a character in the movie and how its influence can be seen in each character. Each character is dealt alone and in groups. It can be known where each character falls; whether to civilized world or to the wilderness nature of forests. Other issues dealt in the paper is how the depiction of forest is viewed by spectators. Does spectators have the same effect concerning the depiction of forests in the way; it was intended to.

Each character is analysed in detail with reference to forest. Iyob, Dimitri, Ivan and Chemban show the characteristics of forest in them. It is the Aloshy who comes from the outside world that disrupts the balance and wilderness of forest and that of characters. Each character is changed due to the entry of Aloshy. The entry of AngoorRawthoor restores the 
violence and wilderness of the forest back. Many characters returned to their real character. But lyob gets changed after the entry of Aloshy and Rawthoor. He sheds his wild nature and puts the attire of human values.

The character of lyob gives the most dominant and brutish nature. The character Dimitri and Ivan are vibrant, passionate and brutish. The characters Rahel and Dimitri are sexually vibrant and conflicting. Chemban and Aloshy have a positive wave but still they are brutish in killing. Chemban is interested in hunting and the same way he kills his rivals by chasing and slaying their heads ritually. Forest is associated with superstitions. This is represented by Kazhali. Aloshy lived a better part of his life in city. But still his inherent influence of forest is revealed through his courageousness. Annama is forest's vitality. Martha is not a feeble character as it appears to. She has an extra-ordinary will power which she acquired due to her life situations in forest. AngoorRawthoor, a brutish outside intruder represents natural calamities which comes silently but destroys everything abruptly.

The brutality starts right from the beginning of the film. The film begins with a Bible verse. "The aged aren't always wise, nor do the elderly always understand justice" Job 32:9. It mainly focuses on Iyob; who thinks that what he does is justice. The power of brutality originates from outside during the pre-independence era which is through the presence of British rule. At the end of the British domain and passed on to the peacefully living people. The peace among people is interrupted by the newly powered Iyob. Iyob is being adopted by Harrison seeing the extra ordinary sign of brutality in his eyes. He is asked to hit and kill his own people. It becomes a pleasure to move around and beat his fellowmen on the instruction of Harrison. On the instruction of his master;Iyob kills the man, who was in affair with Kazhali. After that the first sign of brutality is done to Kazhali; who was the mistress of Harrison. Iyob throws the pregnant Kazhali out' when he knows that Harrison is dead. When Iyob does this brutality Ivan and Demitri were kids. The seeds of Brutality were sowed in 
them. Thus Iyob, Detrmitri and Ivan form a dominating triangle of Brutality. They were well acceptable in forest because of the traits of violence and brutality which was embedded in them.

But Aloshy was not affected with these traits. He got the generous and vitality nature of his mother Annamma. She dies eventually unbarring the sprouting triangle violence of the family. The generous nature of Aloshy is evident to two of his siblings when Iyob tries to teach Aloshy shooting. Keeping this in mind Ivan and Dimitri becomes a dashing force to Aloshy in forest. The generous nature of Aloshy is doomed out of the forest by the violent nature of Dimitri and Ivan. Aloshy runs of from the clutches of brutality when he sees the murder of poor lass done by Ivan and Dimitri. These are the contrast in the character of siblings when they were children. Instead of games and friendships, Ivan and Dimitri were upholding violent activities. But Aloyshy had good friendship with Martha and Chemban.

It was the civilized world which gave shelter to Aloshy who was abandoned by forest. Without Aloshy the forest was well balanced with the dominance of the brutish triangle. When Aloshy returned to the forest then the static nature was disrupted. He had civilized nature embedded in him. Even after along years, when Aloshy came; he was not acceptable to his house. There were attempts made by the Ivan and Dimtri to expel Aloshy out from forest. It was the very attempt made by forest to get rid of a civilized man out from it.

The Communist and Naxals in the movie are representatives of manly nature among brutish men. They stand for the rights of men. The brutish triangle tries to expel and suppress these men. Due to the intervention of Aloshy and Communist; Chemban acquire some humaistic characteristics. After that Chemban is also unwanted in the forest. When Iyob become more humanly, he too is expelled from forest. Thus, the forest expels whoever does not run parallel to its nature. 
Brutish triangle is the very representative of the wilderness of forest. They destory whoever stands against the wild nature. Chemban was filled with vitality of brutish nature. He kills his enemies by chasing and predating just as wild animals do. The wild activity was there till his end. But when Aloshy came, his wild activity was for a cause. When Rawthoor comes in; the brutish triangle of Iyob and sons gets reduced to two. Iyob is touched with a more human nature. The place of Iyob in the triangle is taken by Rawthoor. Since Rawthoor is from outside world, he is not accepted by Iyob. But his sons; Dimitri and Ivan accept him. Rawthoor has the same range of violence as that of the residents in forests. The imbalance created by Aloshy is maintained by Rawthoor. Both are from Civilized World.

The women characters are also important in the film. A wide range of strong-willed women characters are there in the film. Right from the beginning there is Kazhil, Annama, Martha and Rahel in the film. Annama is a soft person who represents the ever shelter nature of forest. Even without Iyob's knowledge she visit's Kazhali and Martha and they gave shelter to a poor orphan lass. After her death the peaceful atmosphere in the house was disrupted and was never attained again. Aloshy was expelled from the house and the poor lass were brutally murdered.

Kazhali and her daughter Martha was very much strong willed. Though they seem to be orphans to the society; they were self-sufficient and know to secure themselves against all dangerous forces. When Martha becomes once again acquainted with her old companion Aloshy, Kazhali dies. Martha becomes alone. When she becomes a victim of brutality, Aloshy saves her. Thus, Martha too becomes as abandoned being in the forest. The will power of Martha is seen even in the time of pregnancy. The mix of civilized world and forests is the child of Aloshy and Martha. But the new brutish triangle does all their efforts to prevent its birth. 
The character of Rahel is very interesting. She is the ever-flirting character in the film. Expect Iyob; she flirts with everyone in the film. Being the wife of Dimitri, she flirts with Ivan, shares bed with him; she tries to flirt with Aloshy and finally she flirts with Rawthoor. She is the lustful brutish force in the film. She disperses desire in all. The desire in Ivan for Rahel kills Demitri. This rivalry and killing is similar to that jealousy between Cane and Abel. She further embeds desire in Rawthoor and asks him to kill Ivan. Thus, she is the destroying force which kills sibling and men of contact. After Ivan and Rawthoor being killed; Rahel is alone in the huge mansion. There is no option than killing herself. The killing act itself is done in a very lustful manner. Thus, Rahel is a character who shows the forest vitality in a lustful manner throughout the film. The end of Rahel marks the end of violence the forests. Whatever is outside the land is generally considered as manly.

There is a lady from communist party who fights for the rights of the ordinary people in the forests. She is from the civilized world. She is very brave and has great will power. Due to this quality, she is suppressed and crushed in all her endeavors. She is the representative of manly from the dominating and wilderness.

In a conversation between Chemban and Aloshy it hints that Tamil men are more kind towards the working class and they do not cease their women. The sons of lyob especially have that brutish quality of captivating women for their pleasure. Aloshy is an exemption. When the brutality is over; the manly communist power acquires the well-being of man. The very story of the film is narrated by a communist's leader who lived during the time of the story. When forests shed all its brutality, many changes occurs to the land. It becomes livelier and more peaceful. Iyob's residence is a mini representative of forest in the film. The closing scene of the movies shows the communist leader in the house. The ever vibrant and brutal Iyob's residence get changed in to a tranquil place. The Change which happened to the forest 
is evident here. Forests gave its way to the civilized culture and it came to be a house to be peacefully lived in.

Forest always gives shelter to all in need. It gave shelter to Harrison, Rawthoor and to Aloshy. At first time thought he was expelled from forests; after many years when he came, he was given shelter. Then when his siblings try to kill him brutally, it was the forests that save him. Forests give him lifeback and restore his health. At last, when it sheds all its violence and brutishness again it is gives shelter to the manly communist and ordinary men. It never holds up its traditions. Through Kazhali, forest uploads its superstitious nature. The manly nature of communists is a wide contrast to the balance of forest is maintained and acquired each time. When Annama dies; the poor orphan girl is murdered, when Aloshy is explode, when Chemban and Martha is unwanted, when Rahel, Ivan, Rawthoor is expelled and finally when it gave place for communist forests maintains its balance. Forests are not static in its nature. It is very dynamic and changes its attitudes with situation and circumstance.

Forest can be seen as an archetype of birth, death, power, rebirth, self-sufficiency, violence and regeneration. All the stages of forest can be seen in the film through characters. The birth of characters in the movie is shown, the death of Kazhali, self-sufficiency of Chemban and his wife, Kazhali and Martha, re-birth of Aloshy when his brothers try to repress him, the violence of Rawthoor like a natural calamity and finally the regeneration of forest back to its calmness by the end of the movie. Forest can also be taken as the mental journey of characters in their own course. "Real Liberation comes not from glossing over or repressing painful states of feeling, but only from experiencing them to the full" (The archetypes and Collective Unconscious- C.G. Jung) The above quote shows that forest has influenced each character in its own way and through the journey with forest they have their own self liberation and self-realization. 
Forest is depicted very well in the film. There should also be a thought that how the depiction is used in the film and how it was felt like. The spectators view 'IyobintePusthakam ' with a difference of opinion. The film was a box office hit. The depiction of forest and surrounding is one major cause. Forest is depicted with such aesthetics as never before. The colour medium used in the film is not the bright one as seen in the films nowadays. It is slightly dim as seen in movies especially that of the 70's. The forest is seen to be dazling and attractive than the real one.

Forests and the natural surroundings are being commercialized in the film. The surrounding of Vagamon and Munnar are taken in the film. Forest is shown as bits and pieces. With the aid of cinematography, it is not felt. The story takes place in forests. The village they show to be in the forest is not the real village. It is a made - up village with men and property. Even the village they represent has a tinge of modernity in it. There are modern film equipments especially in stunts and scenes related to forest life. From a drama film now, it comes to the forefront of media. At this point there is need of using modern techniques to attract spectators. Undoubtedly spectators had grabbed all effects put forward by the film as real. They don't feel that it is a cooked-up movie. They do not distinguish the effects of film and reality.

The costumes given to each character give the characteristic trait of each character. The civilized nature of Aloshy, brutish nature of Iyob, Demiti and Ivan, the traditional dressing of Chemban and Kazhali, the pious nature of Annama is all evident in their costume. Martha's costume and that of communists shows the will power inherent in them. The lustful nature of Rahel is evident in her costume, make- up and her body language. So there is anachronism in the film. The silk sari which Rahel puts in is more of a modern one. The language used in the film especially the bad words seem to be similar. 
In spite of all odes and even the film has a great significance to be studied in all its aspects. It has more allegiance to a new generation style in many aspects; through it is a period movie. Nature's influence on man is very well seen in 'IyobintePusthakam'. The brutality, calmness, love and lust of characters in the movie are very well reflected by nature especially the forest. The movie is the most suitable one for the study of nature and characters. In 'The Religion of the Forest' Tagore says that our frame of mind guides our attempts to establish relation with universe either by conquest or by union through cultivation of power through that of sympathy. Here it is clear that in human life there is either an intermingling with nature or a withdrawal with nature. These are very well shown in the movie taken. The character always associates with the two extremes of forests which is the very essence of the concept told. 


\section{Works Cited}

Basso H, Keith. Wisdom Sits in Place: Landscape and Language Among the Western Apache. University of New Mexico Press,1996.

Jung, Carl. The Archetypes and the Collective Unconscious: The Collected works. Routledge \& Kegan Paul LTD,1991.

Tagore, Rabindranath. Creative Unity. London: Macmillan, 1922.

https://en.wikipedia.org/wiki/Iyobinte_Pusthakam 